\title{
Annoyance and activity disturbance induced by high-speed railway and conventional railway noise: a contrastive case study
}

\author{
Guo-Qing Di* ${ }^{*}$, Qi-Li Lin ${ }^{1}$, Zheng-Guang Li and Jian Kang²
}

\begin{abstract}
Background: High-speed railway (HR, Electrified railway with service speed above $200 \mathrm{~km} / \mathrm{h}$.) noise and conventional railway (CR, Electrified railway with service speed under $200 \mathrm{~km} / \mathrm{h}$.) noise are different in both time and frequency domain. There is an urgent need to study the influence of HR noise and consequently, develop appropriate noise evaluation index and limits for the total railway noise including HR and CR noise.
\end{abstract}

Methods: Based on binaural recording of HR and CR noises in a approximate semi-free field, noise annoyance and activity disturbance induced by maximal train pass-by events in China were investigated through laboratory subjective evaluation. 80 students within recruited 102 students, 40 males and 40 females, $23.9 \pm 2.1$ years old, were finally selected as the subjects. After receiving noise stimulus via headphone of a binaural audio playback system, subjects were asked to express the annoyance or activity disturbance due to railway noise at a 0-100 numerical scale.

Results: The results show that with the same annoyance rating $(A)$ or activity disturbance rating $(D)$, the A-weighted equivalent sound pressure level $\left(L_{\text {Aeq }}\right)$ of $C R$ noise is approximately $7 \mathrm{~dB}$ higher than that of HR noise. Linear regression analysis between some acoustical parameters and $A$ (or D) suggests that the coefficient of determination $\left(R^{2}\right)$ is higher with the instantaneous fast A-weighted sound pressure level $\left(L_{\text {AFmax }}\right)$ than that with $L_{\text {Aeq. }}$. A combined acoustical parameter, $L_{H C}=1.74 L_{A F \max }+0.008 L_{A F \max }\left(L_{p}-L_{A e q}\right)$, where $L_{p}$ is the sound pressure level, was derived consequently, which could better evaluate the total railway noise, including HR and CR noise. More importantly, with a given $L_{H C}$, the noise annoyance of HR and CR noise is the same.

Conclusions: Among various acoustical parameters including $L_{H C}$ and $L_{A e q} A$ and $D$ have the highest correlation with $L_{H C}$. $L_{H C}$ has been proved to be an appropriate index to evaluate the total railway noise, including both HR and CR. However, it should be pointed out that this study provides suggestive evidence, rather than a final proof. Further study is expected to elucidate conclusions above by additional measurements.

Keywords: Noise descriptor, High-speed railway, Evaluation index, Annoyance, Activity disturbance

\section{Background}

The research on high-speed railway (HR) noise has attracted more and more attention. The train noise consists of various sources, such as wheel/rail noise and aerodynamic noise. The aerodynamic noise depends strongly on train speed [1]. In a study of Shinkansen train, which is the high-speed railway train in Japan with the maximum speed of $240 \mathrm{~km} / \mathrm{h}$ $\sim 320 \mathrm{~km} / \mathrm{h}$, it was shown that the aerodynamic noise was

\footnotetext{
* Correspondence: dgq@zju.edu.cn

'Institute of Environmental Pollution \& Control Technology, Zhejiang University, Hangzhou 310058, China

Full list of author information is available at the end of the article
}

dominant sound source of the train noise when the train speed exceeded $270 \mathrm{~km} / \mathrm{h}[2,3]$. Moreover, the duration of HR noise is normally shorter than that of conventional train noise. Consequently, the HR noise and conventional railway (CR) noise are different in both time and frequency domain. Compared with $\mathrm{CR}$ noise, the magnetic levitation railway (MLR) noise is more similar to HR noise [4,5].

The results obtained by field surveys or laboratory studies could provide supports for setting standards for traffic noise. A number of field surveys on CR noise have been carried out in different countries [6]. Commercial HR systems have been built in a number of countries,

\section{() Biomed Central}


including Japan, France and China, but there have been limited reports on the field surveys of HR noise. When Shinkansen was opened in 1964, its noise caused a lot of complaints. As there was no special evaluation standard for this new traffic noise, a field survey was carried out by the Environmental Agency of Japan. Based on the results, the maximum A-weighted equivalent sound level, $L_{\text {ASmax }}$, with the time duration as $1000 \mathrm{~ms}$, was selected to evaluate the HR noise [7]. In 1993, a field survey was carried out to assess the impact of noise induced by the TGV Atlantique line in France [8]. Whilst the A-weighted equivalent sound pressure level, $L_{\text {Aeq }}$, seemed to be a relevant noise annoyance descriptor for the daytime, the number of noise events or the length of time over $70 \mathrm{~dB}$ (A) seemed to be more appropriate for the evening. Based on a field survey in Shanghai on the magnetic levitation rail (MLR) noise impact, Chen et al [9] found that $L_{\mathrm{ASmax}}$ is more appropriate than $L_{\mathrm{Aeq}}$ as a noise descriptor.

Meanwhile, some researchers have compared the impact of the noises from CR, HR and MLR under laboratory conditions. In two relevant laboratory studies reported by Fastl and Gottschling [10,11], the overall (or global) loudness ratings for the MLR and CR noise, with the same $L_{\text {Aeq }}$, were not significantly different. However, in a laboratory study reported by Neugebauer and Ortscheid [12], the subjects were more negative about MLR than CR. Moreover, especially at a higher $L_{\text {Aeq }}$, the sounds from MLR were considerably louder than those of CR. In a laboratory study reported by Vos [13], the annoyance degree caused by MLR was also considerably higher than that by CR. In a study reported by De Coensel et al [5], a holiday cottage was selected as a natural setting, and subjects were asked to engage in simple daily activities during the tests. Using fixed outdoor loudspeakers, railway noise was reproduced. After noise exposure, subjects were asked to evaluate the noise annoyance. The results, however, showed that there was no significant difference among the annoyances caused by CR, HR or MLR noise at same $L_{\text {Aeq }}$. Overall, the above results are inconsistent, which might be caused by the use of different stimuli. According to a laboratory study reported by $\mathrm{Di}$ et al [14], there is a strong correlation between the annoyance and the burst duration and interval time of intermittent noise. In the studies reported by Fastl and Gottschling [10,11], Neugebauer and Ortscheid [12] and Vos [13], pass-by sounds were used and each stimulus included only one noise event. The stimuli used by De Coensel et al [5] included several passby sounds.

In China, the total mileage of HR has exceeded $6900 \mathrm{~km}$ since the first HR was put into operation in 2008. However, no special sound environment quality standard for the area along HR has been set up in China. GB 30962008 [15], which is an "Environmental Quality Standard for Noise" of China, provides evaluation indices and noise limits for different sound environment function areas including the area along $\mathrm{CR}$, i.e. the existing noise limit developed for CR noise is also used for HR. Many residents living along the HR have complained about the noise impact from HR [16,17], so that there is an urgent need to study the influence of HR noise and consequently, develop appropriate noise index and limits.

In this study, therefore, based on binaural recording of $\mathrm{HR}$ and CR noises in a approximate semi-free field, the noise annoyance and activity disturbance have been investigated through laboratory subjective evaluation. The aim is to examine the effects of different acoustical parameters, develop appropriate noise evaluation methods and indicators of total railway considering the two kinds of railway noise.

\section{Methods}

\section{Binaural recording}

The Artificial Head Measurement System HMS IV.0 (Head Acoustics, 2008) was used to sample HR and CR noises, and a digital video recorder was used to record the pass-by trains. The ear height was $1.2 \mathrm{~m}$ above the ground [15].

Acoustical characteristics of railway noise are pertaining to train type and rail track. The most representative train type and rail track was chosen in this study in order to that the research results can be generalized to railway system of China as far as possible. It was also confirmed by the Ministry of Railways of the People's Republic of China that the train type and rail track of HR and CR chosen below has been most widely used now and will be generalized in the future in the railway network of China, especially in the high-speed railway network.

The HR noise was recorded in a semi-free open field along the Shanghai-Hangzhou HR, where rail level was $15 \mathrm{~m}$ higher than ground and the background noise was lower than $35 \mathrm{dBA}$. The recording was made at different distances from the HR, reflecting the attenuation characteristics. In an experiment reported by Kurra [18], the noise was recorded at $30 \mathrm{~m}$ and $100 \mathrm{~m}$ from the outboard track. In the experiment reported by Vos [13], the noise was recorded at $25 \mathrm{~m}, 50 \mathrm{~m}$ and $100 \mathrm{~m}$ from the outboard track. In the experiment reported by De Coensel et al [5], the recording distance was $25 \mathrm{~m}, 50 \mathrm{~m}$, $100 \mathrm{~m}$ and $200 \mathrm{~m}$ from the outboard track. In this study, the recording distance was $20 \mathrm{~m}, 30 \mathrm{~m}, 50 \mathrm{~m}, 100 \mathrm{~m}$ and $200 \mathrm{~m}$ from the outboard track. During the recording, the pass-by trains were of same type (CRH380A, 8 railroadcars), and the speed was $301 \pm 3.6 \mathrm{~km} / \mathrm{h}$.

The CR noise was recorded in a semi-free open field along the Zhejiang-Jiangxi CR, where rail level was $2.3 \mathrm{~m}$ higher than ground and the background noise was also lower than $35 \mathrm{dBA}$. The recording distances corresponded 
to those of HR recording. During the recording, the passby trains were of same type (SS8, 17 railroadcars), and the speed was $107 \pm 10.7 \mathrm{~km} / \mathrm{h}$.

Considering that train noise actually varies from train to train even if the trains are moving with the same speed as the wheel conditions for different trains are not identical, the pass-by trains of same type were recorded 8 times at each distance from the outboard track.

\section{Test stimuli}

The recordings were analyzed using the ArtemiS 10.0 software (Head Acoustics, 2008). It was shown that the duration of pass-by sound was 15-20 s for each HR, and 35-40 s for each CR. In order to include the whole passby sound, the total duration of each sound fragment was fixed as $45 \mathrm{~s}[5,13]$, with the maximum level at about $22.5 \mathrm{~s}$. The standard errors of $L_{\mathrm{AS} \max }$ and $L_{\mathrm{Aeq}}$ over $45 \mathrm{~s}$ for 8 recorded pass-by trains at the same distance from the outboard track were $3.0 \mathrm{~dB}$ and $2.0 \mathrm{~dB}$, respectively. One recorded pass-by train, whose $L_{\mathrm{ASmax}}$ and $L_{\mathrm{Aeq}}$ is closest to the average, was then chosen among 8 recorded pass-by trains. Finally, ten sound fragments were prepared, five for HR and five for CR, each corresponding to a distance from the outboard track. The total level of the noise sample $L_{\mathrm{S}}(\mathrm{dB})$ is calculated [19] by

$$
L_{\mathrm{S}}=\lg \frac{10^{L_{\mathrm{L}}}+10^{L_{\mathrm{R}}}}{2}
$$

where $L_{\mathrm{L}}$ is the level of the left signal $(\mathrm{dB})$, and $L_{\mathrm{R}}$ is the level of the right signal $(\mathrm{dB})$. The difference between $L_{\mathrm{L}}$ and $L_{\mathrm{R}}$ is less than $1.0 \mathrm{~dB}$.

The sound pressure level (SPL) in 1/3-octave bands are illustrated in Figure 1 for each sound fragment. It can be seen that with increasing frequency, the HR SPL decreases continuously, and this tendency is relatively less significant for CR. To examine this in more detail, a time-frequency analysis of the noise recorded at $20 \mathrm{~m}$ from the outboard track has been carried out, as shown in Figure 2. It can be seen that the low frequency noise of HR is more prominent compared with CR.

In the laboratory study of traffic noise reported by De Coensel et al [5], Kurra [18], Vogt [20] and Sandrock et al [21], the test duration for subjective evaluation was 10-30 min. In the experiments where the duration of 30 min was used, subjects were asked to engage in two activities [18]. In other experiments, subjects were asked to engage in only one activity. In this study, $15 \mathrm{~min}$ was used as the test duration, which included six pass-by sounds with a constant interval that was determined based on train schedule, where the maximum train passby was approximately 24 per hour. In the studies carried out by De Coensel et al [5] and Kurra [18], a similar train frequency was used. During the test of activity
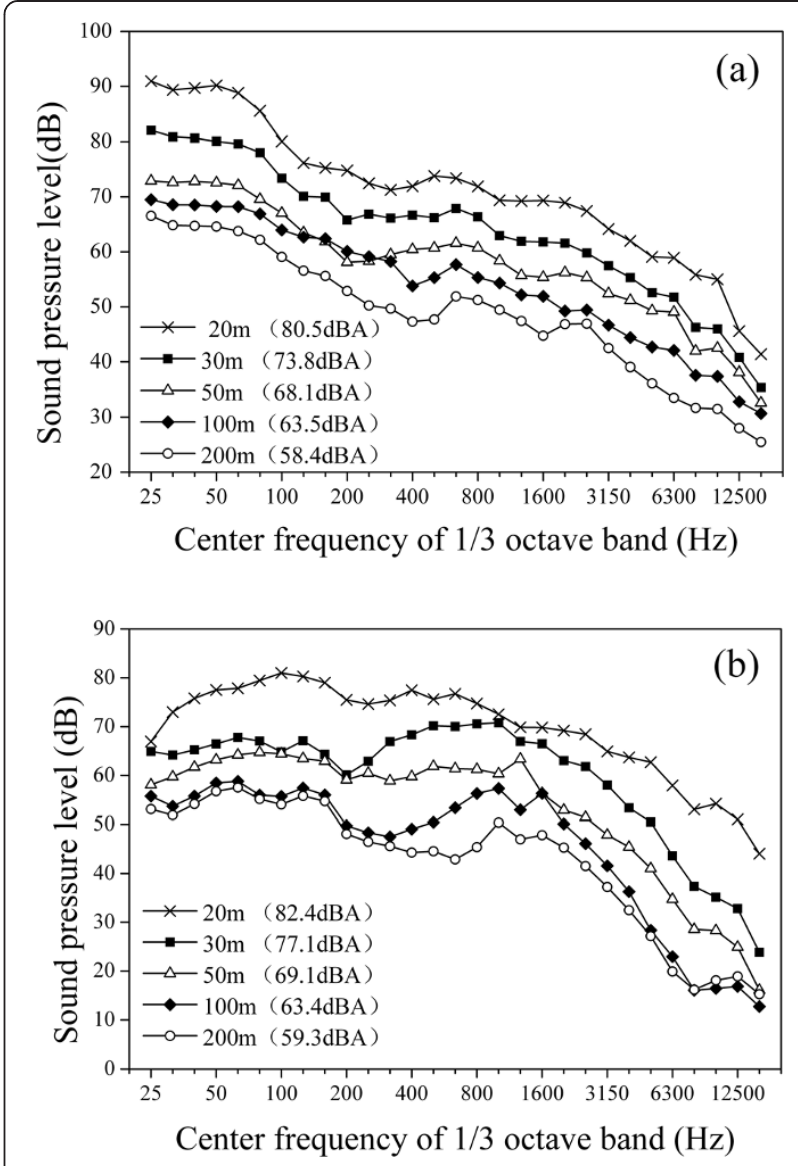

Figure $1 \mathrm{SPL}$ in $1 / 3$-octave bands for 10 sound fragments. (a) High-speed train (HR); (b) Conventional train (CR).

disturbance, subjects were asked to engage in one activity, as described below.

\section{Subjective evaluation}

The noise annoyance and activity disturbance induced by maximal train pass-by events in China (six pass-by sounds with a constant interval over $15 \mathrm{~min}$ ) were investigated through laboratory subjective evaluation.

The binaural audio playback system consisted of four headphones (Sennheiser HD-600), a distribution amplifier (Head AcoustiAS HDA IV. 1) and a digital equalizer (Head AcoustiAS PEQ V). Headphones outputs were calibrated at the calibration laboratory of the HEAD acoustics GmbH. The differences of sound pressure level between nominal value and actual value for left channel or right channel of Headphones are all lower than $0.05 \mathrm{~dB}$. The experiment was performed in a soundproof room ( $4 \mathrm{~m}$ by $4 \mathrm{~m}$ by $3 \mathrm{~m}$ ), where the background noise was lower than $25 \mathrm{dBA}$.

In the first stage 102 students were recruited to take part in a hearing test, which was performed using an audiometer to test the hearing loss of each student. After 

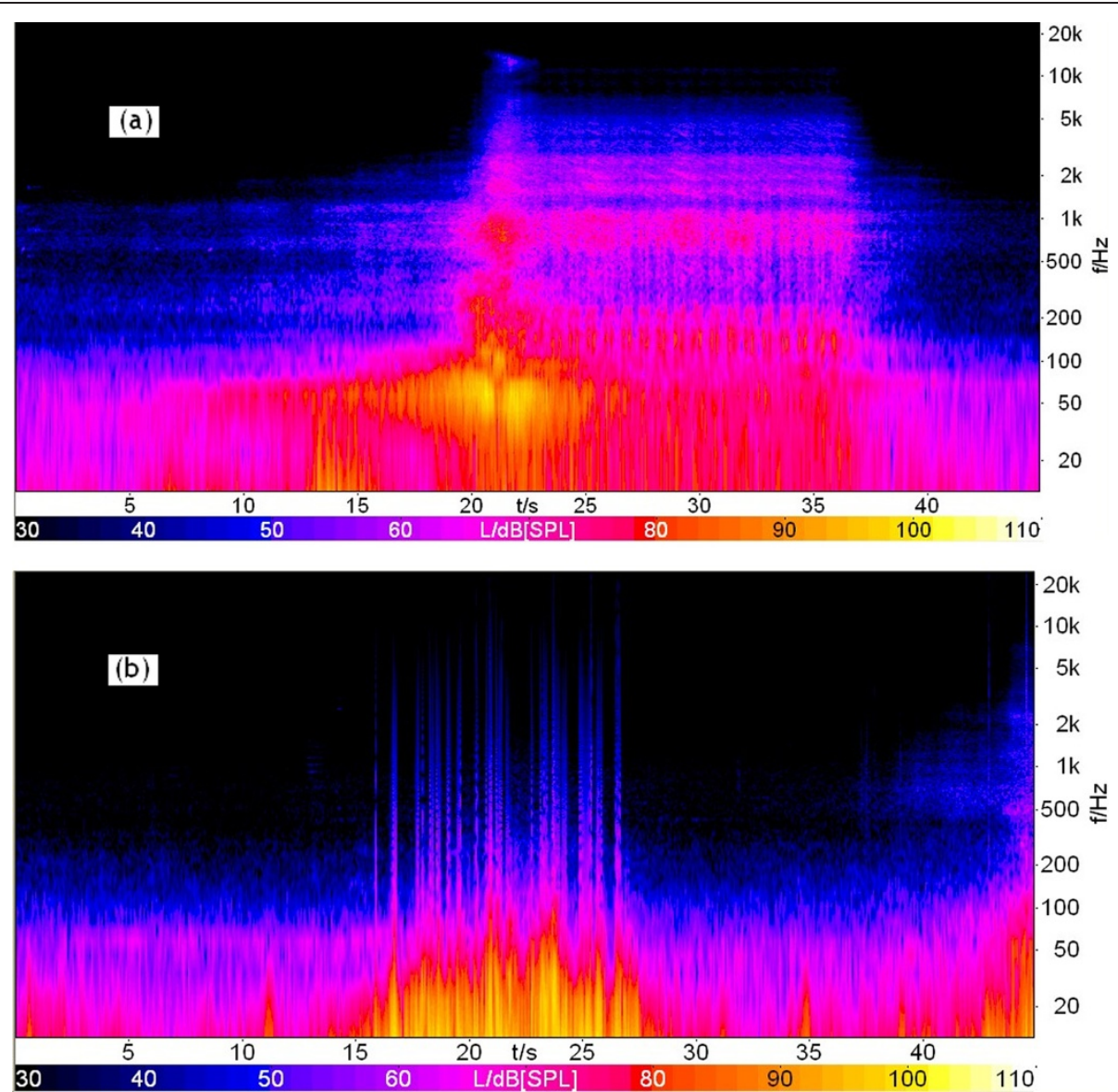

Figure 2 A time-frequency analysis of railway noises recorded at $20 \mathrm{~m}$ from the outboard track. (a) CR; (b) HR.

excluding one student having an obvious hearing loss (>15 dB) [22] and 21 students whose curriculum schedules were conflicting with scheming experimental timetable, 80 students, 40 males and 40 females, $23.9 \pm$ 2.1 years old, were finally selected as the subjects for subjective evaluation experiments. Since the binaural audio playback system consisted of four sets of headphones, only four subjects could receive noise exposure at the same time through headphones. 80 subjects were divided into 20 groups randomly. Each group included 4 subjects. Two independent experiments, annoyance and activity disturbance induced by railway noise, were carried out, respectively [23].

A numeric rating scale $[24,25]$ was used to evaluate annoyance and activity disturbance induced by noise in this study. Before experiments, the subjects were told that the purpose of this experiment was to evaluate the annoyance and activity disturbance induced by railway noise. They were also asked to imagine they were in the outdoor environment and the recorded environmental background noise and video along the railway were presented by a dodecahedron loudspeaker and a television [26].
When experiments began, the dodecahedron loudspeaker was turned off and subjects received noise stimulus via headphone of a binaural audio playback system above. Previous study $[27,28]$ reported that the visual settings influenced judgments on annoyance induced by noise. In order to reduce the impact of visual setting on the study, it is necessary to reproduce the original scene truly. In this study, the recorded video, including pass-by trains, was played back simultaneously with sounds. In the experiment of activity disturbance induced by noise, subjects were asked to select magazines to read individually during noise exposure [26]. After above noise exposure, subjects were asked to express the annoyance or activity disturbance due to railway noise at a 0-100 numerical scale [29], where 0 means 'Not at all', and 100 means 'Extremely' [24,30-33]. Since all the subjects in this study were university students with good English level, the evaluation sheet was both in English and Chinese.

\section{Data processing and statistical analysis}

The annoyance rating $(A)$ and activity disturbance rating $(D)$ of each noise sample was calculated by averaging 
scores chosen by all subjects. Acoustical parameters (such as $L_{\text {Aeq }}, L_{\text {AFmax }}, L_{\mathrm{N}}$, etc.) of each noise sample were calculated by ArtemiS 10.0 software. All statistical analyses were performed by Origin 7.5 (OriginLab Corporation, Northampton, MA, USA). Three kinds of regression models, including linear model, second-order polynomial model and exponential model, were used to examine relationships between $A$ ( or $D$ ) and each single acoustical parameter above. The regression model with the highest determination coefficient was given. In order to further develop an appropriate evaluation index for the total railway noise including $\mathrm{HR}$ and $\mathrm{CR}$, a multiple regression model was used to examine relationships between combined acoustical parameters and $A$ ( or $D$ ) of overall railway noise, including HR and CR. $L_{\mathrm{AFmax}}$ and $L_{\mathrm{p}}-L_{\text {Aeq }}$ were chosen as acoustical parameters in multiple regression model which was given as below.

$$
\begin{aligned}
& A=\mathrm{a}_{1} L_{\text {AFmax }}+\mathrm{b}_{1} L_{\text {AFmax }}\left(L_{\mathrm{p}}-L_{\text {Aeq }}\right)-\mathrm{c}_{1} \\
& D=\mathrm{a}_{2} L_{\text {AFmax }}+\mathrm{b}_{2} L_{\text {AFmax }}\left(L_{\mathrm{p}}-L_{\text {Aeq }}\right)-\mathrm{c}_{2}
\end{aligned}
$$

where $a_{1}, a_{2}, b_{1}, b_{2}, c_{1}, c_{2}$ are all constant terms.

\section{Results}

The relationships between the subjective evaluation results and $L_{\text {Aeq }}$ of stimuli were then analyzed. Figure 3 (a) shows the relationship between $A$ and $L_{\text {Aeq. }}$. It can be seen that $A$ increases with increasing $L_{\text {Aeq }}$. Based on comparing the coefficient of determination $\left(R^{2}\right)$ of three kinds of regression models (linear model, second-order polynomial model and exponential model), linear regression model having highest $R^{2}$ was chosen to describe the relationship between $A$ and $L_{\text {Aeq }}$. The model for HR is given below, where the coefficient of determination $\left(R^{2}\right)$ is 0.993 ,

$$
A=2.05 L_{\text {Aeq }}-72.9
$$

For CR, the model is given below, where $R^{2}=0.991$,

$$
A=2.06 L_{\text {Aeq }}-86.6
$$

From the above it can be derived that with the same $L_{\text {Aeq }}, A$ of HR noise is approximately 13.0-13.2 higher than that of CR noise. With the same $A, L_{\mathrm{Aeq}}$ of CR noise is approximately 6.3-6.4 dB higher than that of HR noise. Compared with CR noise, for HR noise the peak level of train events $\left(L_{\mathrm{A} \max }\right)$ and the proportion of low frequency sound energy are generally higher and the duration of noise is shorter $[8,10,14]$, which could result in greater annoyance of HR noise compared with that of CR noise at the same $L_{\text {Aeq }}$.

Figure 3 (b) shows the relationship between $D$ and $L_{\text {Aeq. }}$ Similar to the relationship between $A$ and $L_{\text {Aeq, }}$, with increasing $L_{\text {Aeq }}, D$ increases, and the relationship
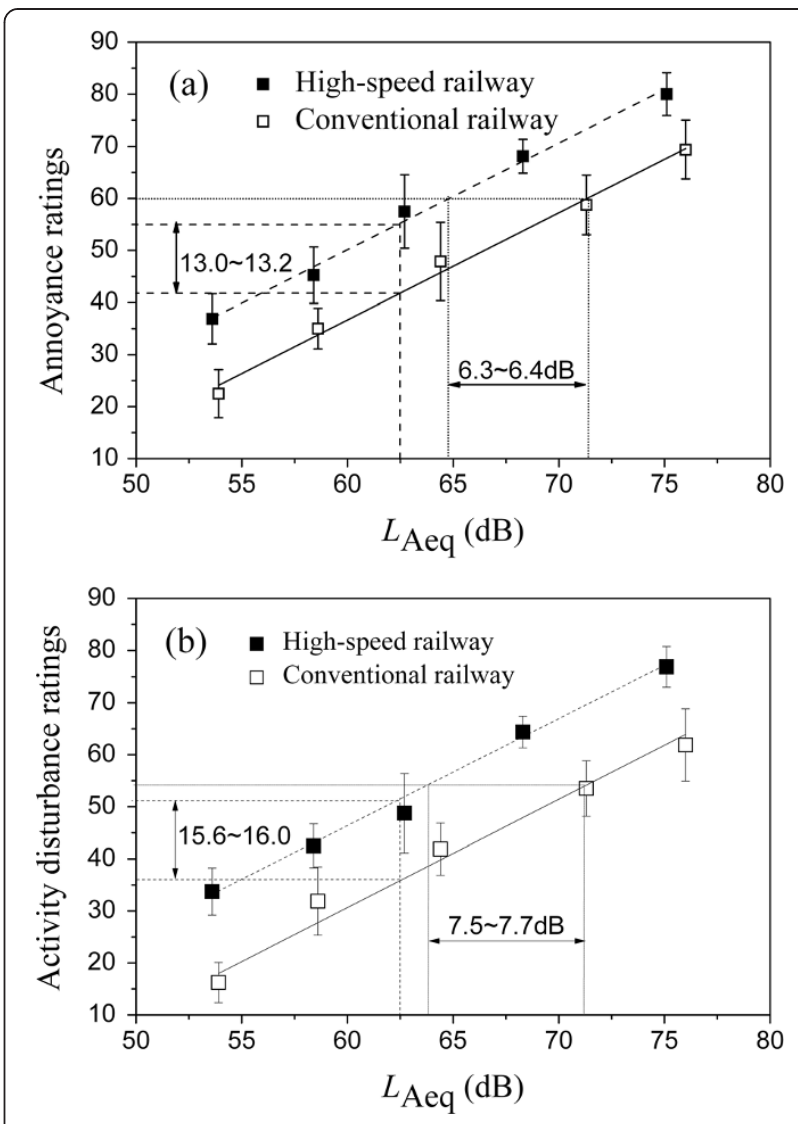

Figure 3 The relationships between $A$ and $L_{\text {Aeq }}$, and between $D$ and $L_{\text {Aeq. }}$ (a) Between $A$ and $L_{\text {Aeq. }} . H R: A=2.05 L_{\text {Aeq }}-72.9\left(R^{2}=0.993\right)$; $C R: A=2.06 L_{\text {Aeq }}-86.6\left(R^{2}=0.991\right) ;(b)$ Between $D$ and $L_{\text {Aeq. }} . H R: D=2.06 L_{\text {Aeq }^{-}}$ $77.0\left(R^{2}=0.994\right) ; C R: D=2.08 L_{\text {Aeq }}-94.1\left(R^{2}=0.978\right)$.

for HR can be given below, where the coefficient of determination $\left(R^{2}\right)$ is 0.994 ,.

$$
D=2.06 L_{\text {Aeq }}-77.0
$$

For CR, the relationship between $D$ and $L_{\text {Aeq }}$ is given below, where $R^{2}=0.994$,

$$
D=2.08 L_{\text {Aeq }}-94.1
$$

It can be derived that with the same $L_{\text {Aeq }}, D$ of $H R$ noise is approximately 15.6-16.0 higher than that of CR noise, whereas with the same $D, L_{\text {Aeq }}$ of CR noise is approximately 7.5-7.7 $\mathrm{dB}$ higher than that of HR noise.

Using multiple regression model, the relationships between combined acoustical parameters and $A, D$ of overall railway noise, including HR and CR, were obtained as Eq. (8) and Eq. (9), where $R^{2}$ are 0.991 and 0.977 , respectively.

$$
\begin{aligned}
& A=1.74 L_{\text {AFmax }}+0.008 L_{\text {AFmax }}\left(L_{\mathrm{p}}-L_{\text {Aeq }}\right)-89.7 \\
& D=1.74 L_{\text {AFmax }}+0.008 L_{\text {AFmax }}\left(L_{\mathrm{p}}-L_{\text {Aeq }}\right)-94.8
\end{aligned}
$$


Defining $L_{\mathrm{HC}}=1.74 L_{\mathrm{AFmax}}+0.008 L_{\mathrm{AFmax}}\left(L_{\mathrm{p}}-L_{\mathrm{Aeq}}\right)$, equations above can be simplified to Eq. (10) and Eq. (11) as below.

$$
\begin{aligned}
& A=L_{\mathrm{HC}}-89.7 \\
& D=L_{\mathrm{HC}}-94.8
\end{aligned}
$$

Comparing with linear regression models having single acoustical parameter in Table 1, the determination coefficient $\left(R^{2}\right)$ of the multiple regression model having combined acoustical parameters is higher.

\section{Discussion}

To develop the environmental noise limits, the practicality should be also considered. It would be useful to develop a single index which could be applied for both HR and $C R$ noise, namely, with the same limit value when such an index is used. In addition to $L_{\text {Aeq }}$, relationships between some acoustical parameters and the subjective evaluation results have been analyzed. The acoustical parameters include sound exposure level, $S E L$, which is a indicator on the total noise energy produced by a single noise event; the maximum of the instantaneous fast Aweighted sound pressure level with a duration of $125 \mathrm{~ms}$, $L_{\mathrm{AFmax}}$; the maximum of the instantaneous slow Aweighted sound pressure level with a duration of $1000 \mathrm{~ms}$, $L_{\mathrm{ASmax}}$ [34,35]; the percentile levels, $L_{\mathrm{A} 10}$, which is exceeded by $10 \%$ of measured data during the total measurement time period; in particular [19], the effective perceived noise levels, $L_{\mathrm{EPN}}$, which can be obtained by analyzing one pass-by sound, based on the calculation method reported in ISO 3891-1978 [36]; and four psychoacoustics parameters including loudness levels $\left(L_{\mathrm{N}}\right)$, the sound pressure level of a $1 \mathrm{kHz}$ tone sounding as loud as a noise event; sharpness $(S)$, an index describing high-frequency characteristics of a sound sample; roughness $(R)$, an indicator on sound qualities associating with amplitude modulations caused by tones above $20 \mathrm{~Hz}$; and fluctuation $(F)$, an indicator on sound qualities associating with amplitude modulations caused by tones below $20 \mathrm{~Hz}$ [37], both over $15 \mathrm{~min}$ including quiet periods and over just $45 \mathrm{~s}$. The results are shown in Table 1.

Generally speaking, the ambient noise is not only from one source. Considering combinations of various noise sources, $L_{\text {Aeq }}$ is the most commonly used noise descriptor in environmental noise standards and regulations. As shown in Table 2, $L_{\text {Aeq }}$ is also the most important index for evaluating railway noise. In addition, $L_{\mathrm{AFmax}}$ and $L_{\mathrm{ASmax}}$ are normally selected to evaluate the noise with impulsive character. $L_{\mathrm{AFmax}}$ has been used for emission values for trains [38]. $L_{\mathrm{ASmax}}$ was selected to evaluate the HR noise by the Environmental Agency of Japan [39] and Taiwan [40].

Table 3 shows the $L_{\mathrm{Aeq}}$ and $L_{\mathrm{p}}$ over $15 \mathrm{~min}$ for different stimuli sampled at different distance from the outboard track. As shown in Table 3, the differences between the total un-weighted SPL and $L_{\text {Aeq }}\left(L_{\mathrm{p}}-L_{\text {Aeq }}\right)$ were 20.0-24.7 dB for HR noise, and 8.3-15.4 dB for CR noise. This suggests that compared with $C R$ noise, the proportion of low frequency sound energy is larger for HR noise, which could result in greater annoyance of HR noise compared with that of CR noise at the same

\begin{tabular}{|c|c|c|c|c|}
\hline Acoustical parameters & $A$ & $R^{2}$ & $D$ & $R^{2}$ \\
\hline$L_{\text {Aeq }}$ & $A=1.986 L_{\mathrm{Aeq}^{-}}-75.46^{\mathrm{a}}$ & 0.839 & $D=1.968 \mathrm{~L}_{\mathrm{Aeq}}-79.59^{\mathrm{a}}$ & 0.816 \\
\hline SEL & $A=1.986$ SEL-134. $1^{\mathrm{a}}$ & 0.839 & $D=1.968$ SEL-137. $7^{\mathrm{a}}$ & 0.816 \\
\hline$L_{\text {AFmax }}$ & $A=1.873 L_{\text {AFmax }}-88.63^{\mathrm{a}}$ & 0.942 & $D=1.852 L_{\text {AFmax }}-92.38^{\mathrm{a}}$ & 0.913 \\
\hline$L_{\text {ASmax }}$ & $A=1.939 L_{\text {ASmax }}-84.86^{\mathrm{a}}$ & 0.884 & $D=1.917 L_{\text {ASmax }}-88.58^{\mathrm{a}}$ & 0.856 \\
\hline$L_{\mathrm{A} 10}$ & $A=1.964 L_{\mathrm{A} 10^{-}}-63.40^{\mathrm{a}}$ & 0.653 & $D=1.989 L_{\mathrm{A} 10^{-}}-70.19^{\mathrm{a}}$ & 0.663 \\
\hline$L_{\text {EPN }}$ & $A=1.886 L_{E N^{-1}}-116.9^{b}$ & 0.711 & $D=1.857 L_{E N^{-}}-119.5^{b}$ & 0.683 \\
\hline \multirow[t]{2}{*}{$L_{N}$} & $A=12.15 L_{N^{-}}-740.5^{a}$ & 0.830 & $D=12.34 L_{N^{-}}-757.9^{a}$ & 0.848 \\
\hline & $A=2.218 L_{N}-132.3^{b}$ & 0.782 & $D=2.177 L_{N^{-}} 133.9^{b}$ & 0.757 \\
\hline \multirow[t]{2}{*}{$S$} & $A=171.55 S-177.1^{\mathrm{a}}$ & 0.707 & $D=170.76 S-181.3^{\mathrm{a}}$ & 0.695 \\
\hline & $A=38.62 S-16.50^{b}$ & 0.751 & $D=38.525-21.27^{b}$ & 0.752 \\
\hline \multirow[t]{2}{*}{ R } & $A=-50.91 R+103.4^{\mathrm{a}}$ & 0.341 & $D=-50.06 R+97.23^{\mathrm{a}}$ & 0.327 \\
\hline & $A=23.36 R+2.172^{b}$ & 0.635 & $D=22.98 R-1.978^{\mathrm{b}}$ & 0.618 \\
\hline \multirow[t]{2}{*}{$F$} & $A=6009.7 F+26^{a}$ & 0.496 & $D=6183.7 F+19^{a}$ & 0.520 \\
\hline & $A=2294.1 F+17.87^{b}$ & 0.580 & $D=2324 F+12.48^{b}$ & 0.599 \\
\hline$L_{H C}$ & $A=L_{H C}-89.7^{\mathrm{a}}$ & 0.991 & $D=L_{H C}-94.8^{\mathrm{a}}$ & 0.977 \\
\hline
\end{tabular}

Table 1 The relationships between the subjective evaluation results (both HR and CR) and acoustical parameters

aver $15 \mathrm{~min}$, bover just $45 \mathrm{~s}$. 
Table 2 Noise limits $\left(L_{\text {Aeq }}\right)$ of the areas along railways

\begin{tabular}{|c|c|c|c|c|c|c|c|}
\hline \multirow[t]{2}{*}{ Region } & \multirow[t]{2}{*}{ Type of area } & \multicolumn{2}{|l|}{ HR noise/dB } & \multicolumn{2}{|c|}{ CR noise/dB } & \multicolumn{2}{|l|}{$\begin{array}{c}\text { Difference between CR } \\
\text { and } \mathrm{HR} / \mathrm{dB}\end{array}$} \\
\hline & & Daytime & Night & Daytime & Night & Daytime & Night \\
\hline China & - & 63 & 53 & 70 & 60 & 7 & 7 \\
\hline Belgium & - & 60 & 50 & 65 & 60 & 5 & 10 \\
\hline \multirow[t]{5}{*}{ France } & Hospital, social buildings & 60 & 55 & 63 & 58 & 3 & 3 \\
\hline & Schools & 60 & - & 63 & - & 3 & - \\
\hline & $\begin{array}{l}\text { Dwellings in pre-existing moderate } \\
\text { sound environment zones* }\end{array}$ & 60 & 55 & 63 & 58 & 3 & 3 \\
\hline & Other dwellings & 65 & 60 & 68 & 63 & 3 & 3 \\
\hline & $\begin{array}{l}\text { Office buildings in pre-existing moderate } \\
\text { sound environment zones }\end{array}$ & 65 & - & 68 & - & 3 & - \\
\hline \multirow[t]{2}{*}{ Taiwan } & Hospital, school, dwelling & 65 (Morning, evening) 70(Day)** & 60 & 73 & 70 & 8 (Morning, evening) 3(Day) & 10 \\
\hline & $\begin{array}{l}\text { Mixed areas, commercial areas, industrial } \\
\text { areas }\end{array}$ & 70 (Morning, evening) 75(Day) & 65 & 75 & 70 & 5 (Morning, evening) 0 (Day) & 5 \\
\hline
\end{tabular}

*Moderate sound environment zones are the areas where the environmental noise level existing before the new infrastructure.

**Daytime is divided into morning (5:00-7:00), day (7:00-20:00) and evening (20:00-22:00).

$L_{\text {Aeq. }}$ Through a detailed analysis, it has been proved that the higher low frequency content compared with that of CR could not be due to the noise summation within "no train" period in Figure 2. Generally speaking, as the propagation distance increases, the proportion of low frequency sound energy would also increase. Consequently, $L_{\mathrm{p}}-L_{\mathrm{Aeq}}$ of CR noise increases monotonically, with increasing distance from the outboard track. For $\mathrm{HR}$, however, due to the influence of elevated track, the $L_{\mathrm{p}}-L_{\text {Aeq }}$ does not increase monotonically.

As a combined acoustical parameter proposed to evaluate the total railway noise, $L_{\mathrm{HC}}=1.74 L_{\mathrm{AFmax}}+$ $0.008 L_{\text {AFmax }}\left(L_{\mathrm{p}}-L_{\text {Aeq }}\right)$, where $L_{\text {AFmax }}$ could express the influence of impulsive character, and $L_{\mathrm{p}}-L_{\text {Aeq }}$ could express the influence of low frequency character, which is

Table $3 L_{\text {Aeqr }} L_{p}$ and $L_{\text {Aeq }}-L_{p}$ of stimuli sampled at different distance from outboard track of HR and CR

\begin{tabular}{lcccc}
\hline Stimuli & & $L_{\text {Aeq }}$ & $L_{\mathbf{p}}$ & $\boldsymbol{L}_{\mathbf{p}}-\boldsymbol{L}_{\text {Aeq }}$ \\
\hline $\mathrm{HR}$ & $20 \mathrm{~m}^{\mathrm{a}}$ & 75.1 & 99.8 & 24.7 \\
& $30 \mathrm{~m}$ & 68.3 & 88.4 & 20.1 \\
& $50 \mathrm{~m}$ & 62.7 & 82.7 & 20.0 \\
& $100 \mathrm{~m}$ & 58.4 & 78.6 & 20.2 \\
& $200 \mathrm{~m}$ & 53.6 & 76.8 & 23.2 \\
$\mathrm{CR}$ & $20 \mathrm{~m}$ & 76.0 & 84.6 & 8.6 \\
& $30 \mathrm{~m}$ & 71.3 & 81.7 & 10.4 \\
& $50 \mathrm{~m}$ & 64.4 & 76.0 & 11.6 \\
& $100 \mathrm{~m}$ & 58.6 & 70.9 & 12.3 \\
& $200 \mathrm{~m}$ & 53.9 & 67.8 & 13.9 \\
\hline
\end{tabular}

${ }^{\mathrm{a}}$ The distance between noise sampling site and the outboard track. very different between $H R$ noise and CR noise as shown in Figure 1 and Figure 2. As a result, it is expected that both $\mathrm{HR}$ and CR can be taken into account in the same set of equations. $L_{\mathrm{p}}-L_{\text {Aeq }}$ will decrease with the interval of train pass-by events increasing, i.e., the influence ( $A$ or $D$ ) induced by railway noise will decrease and be lower than that of maximum train pass-by events.

Compared with regression models of $A$ and $D$ in $L_{\text {Aeq }}$ for only HR noise or CR noise (Eq. (4) - Eq. (7)), the combined model of $L_{\mathrm{HC}}$ for total railway noise (Eq. (8) and - Eq. (9)) has additional advantages as discussed below. In Figure 4 the relationships between acoustical parameters of HR noise and CR noise are given. According to the regression equations between $L_{\mathrm{AFmax}}$ and $L_{\text {Aeq }}$, and between $L_{\mathrm{p}}$ and $L_{\text {Aeq }}$, as shown in the caption of Figure 4 , it can be calculated that when $L_{\mathrm{Aeq}}$ is $60.0 \mathrm{~dB}, L_{\mathrm{AFmax}}$ and $L_{\mathrm{p}}$ of $\mathrm{HR}$ are $72.0 \mathrm{~dB}$ and $82.1 \mathrm{~dB}$; and $L_{\mathrm{AFmax}}$ and $L_{\mathrm{p}}$ of $\mathrm{CR}$ are $68.8 \mathrm{~dB}$ and $71.9 \mathrm{~dB}$, respectively. When $L_{\text {Aeq }}$ is $70.0 \mathrm{~dB}, L_{\mathrm{AFmax}}$ and $L_{\mathrm{p}}$ of $\mathrm{HR}$ are $82.8 \mathrm{~dB}$ and $91.6 \mathrm{~dB} ; L_{\mathrm{AFmax}}$ and $L_{\mathrm{p}}$ of $\mathrm{CR}$ are $79.7 \mathrm{~dB}$ and $78.9 \mathrm{~dB}$, respectively. Then they are substituted into Eq. (8), and when $L_{\text {Aeq }}$ is $60.0 \mathrm{~dB}$ and $70.0 \mathrm{~dB}$, the difference in $A$ between HR noise and CR noise is 11.7 and 14.0, which is not identical. However, according to Figure 3 or Eq. (4) and (5), when $L_{\text {Aeq }}$ is $60.0 \mathrm{~dB}$ and $70.0 \mathrm{~dB}$, the difference in $A$ between HR noise and CR noise is 13.1 and 13.0, which is basically identical. Similar results about the difference in $D$ between HR noise and CR noise can be derived from Eq. (6), (7) and (9) when $L_{\text {Aeq }}$ is $60.0 \mathrm{~dB}$ and $70.0 \mathrm{~dB}$.

In fact, based on the regression equations between $L_{\mathrm{AFmax}}$ and $L_{\mathrm{Aeq}}$, and between $L_{\mathrm{p}}$ and $L_{\text {Aeq }}$ given in the caption of Figure 4, Eq. (12) for HR noise and Eq. (13) 


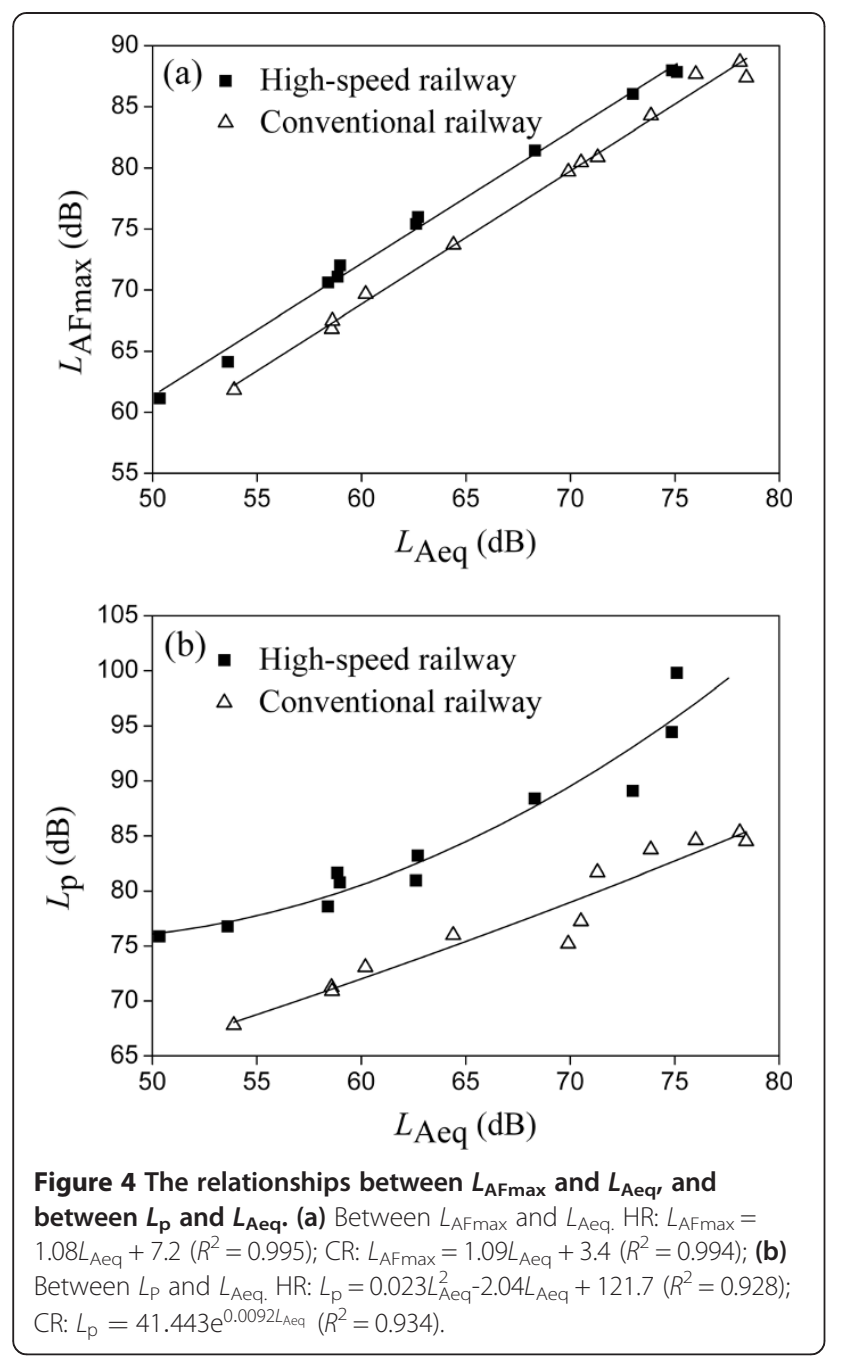

for CR noise between $L_{\mathrm{HC}}$ and $L_{\mathrm{Aeq}}$ can be derived as follows.

$$
\begin{aligned}
L_{\mathrm{HC}}= & 1.74\left(1.08 L_{\text {Aeq }}+7.2\right)+0.008\left(1.08 L_{\text {Aeq }}+7.2\right) \\
& \left(0.023 L_{\text {Aeq }}{ }^{2}-2.04 L_{\text {Aeq }}+121.7-L_{\text {Aeq }}\right) \\
L_{\mathrm{HC}}= & 1.74\left(1.09 L_{\text {Aeq }}+3.4\right)+0.008\left(1.09 L_{\text {Aeq }}+3.4\right) \\
& \left(41.443 e^{0.0092 L_{\text {Aeq }}}-L_{\text {Aeq }}\right)
\end{aligned}
$$

According to Eq. (8), (9), (12) and (13), $L_{\mathrm{HC}}$ of $\mathrm{HR}$ and CR noises with same $A$ were calculated and were listed in Table 4. Results indicate that $L_{\mathrm{HC}}$ of $\mathrm{HR}$ and $\mathrm{CR}$ noises with same $A$ is identical basically.

These results above suggest that compared with the single model in $L_{\text {Aeq }}$ for only HR noise or CR noise, the

\begin{tabular}{|c|c|c|c|c|c|c|}
\hline \multirow[t]{2}{*}{$A$} & \multicolumn{3}{|c|}{$L_{\text {Aeq }}$} & \multicolumn{3}{|c|}{$L_{\mathrm{HC}}$} \\
\hline & HR & CR & CR-HR & HR & CR & CR-HR \\
\hline 25 & 47.8 & 54.2 & 6.4 & 115.9 & 115.7 & -0.2 \\
\hline 28 & 49.2 & 55.6 & 6.4 & 118.4 & 118.3 & -0.1 \\
\hline 31 & 50.7 & 57.1 & 6.4 & 121.0 & 121.0 & 0.0 \\
\hline 34 & 52.1 & 58.5 & 6.4 & 123.6 & 123.7 & 0.1 \\
\hline 37 & 53.6 & 60.0 & 6.4 & 126.2 & 126.3 & 0.1 \\
\hline 40 & 55.1 & 61.5 & 6.4 & 128.8 & 128.9 & 0.1 \\
\hline 43 & 56.5 & 62.9 & 6.4 & 131.5 & 131.6 & 0.1 \\
\hline 46 & 58.0 & 64.4 & 6.4 & 134.2 & 134.2 & 0.0 \\
\hline 49 & 59.5 & 65.8 & 6.3 & 137.0 & 136.8 & -0.2 \\
\hline 52 & 60.9 & 67.3 & 6.4 & 139.8 & 139.5 & -0.3 \\
\hline 55 & 62.4 & 68.7 & 6.3 & 142.6 & 142.1 & -0.5 \\
\hline 58 & 63.9 & 70.2 & 6.3 & 145.5 & 144.7 & -0.8 \\
\hline
\end{tabular}
combined model using $L_{\mathrm{HC}}$ for total railway noise can distinguish the difference of $A$ (or $D$ ) between HR noise
Table $4 L_{\text {Aeq }}$ and $L_{H C}$ of HR and CR noises with same $A$

and CR noise with different $L_{\text {Aeq. }}$ Moreover, when $L_{\text {Aeq }}$ of $\mathrm{HR}$ is $63 \mathrm{~dB}$ and $L_{\mathrm{Aeq}}$ of $\mathrm{CR}$ is $70 \mathrm{~dB}$, whose annoyance $(A)$ is the same, $L_{\mathrm{HC}}$ is approximately 126 ; when $L_{\mathrm{Aeq}}$ of $\mathrm{HR}$ is $53 \mathrm{~dB}$ and $L_{\mathrm{Aeq}}$ of $\mathrm{CR}$ is $60 \mathrm{~dB}, L_{\mathrm{HC}}$ is approximately 144 . In other words, if $A$ of HR noise and CR noise with different $L_{\mathrm{Aeq}}$ is the same, $L_{\mathrm{HC}}$ will be identical. As a result, compared with $L_{\mathrm{Aeq}}, L_{\mathrm{HC}}$ would be a better evaluation index of total railway noise. This can also be seen in Table 1, where among various acoustical parameters including $L_{\mathrm{HC}}, L_{\mathrm{Aeq}}, S E L, L_{\mathrm{AFmax}}, L_{\mathrm{ASmax}}$, $L_{\mathrm{A} 10}, L_{\mathrm{EPN}}, L_{\mathrm{N}}, S, R$ and $F, A$ and $D$ have the highest correlation with $L_{\mathrm{HC}}$.

In many cases, $\mathrm{HR}$ and $\mathrm{CR}$ noises are coexistent in an actual environment. As the limits of both HR noise and CR noise are different in $L_{\text {Aeq }}$, each noise has to be distinguished and measured from total railway noise. However, the limit of $L_{\mathrm{HC}}$ of both HR noise and CR noise is identical, so two types of railway noises can be measured synchronously.

When there are combinations of various noise sources, such as railway and road traffic [41], $L_{\text {Aeq }}$ might be a more general noise evaluation index. However, a single index, $L_{\text {Aeq }}$, would not be sufficient to evaluate the influence of railway noise, as discussed above, it might be possible to use multiple indices such as $L_{\mathrm{Aeq}}, L_{\mathrm{p}}$ and $L_{\mathrm{Amax}}\left(L_{\mathrm{AFmax}}\right.$ or $\left.L_{\mathrm{ASmax}}\right)$. There might be also a scope of modifying $L_{\mathrm{HC}}$ for combined noise sources.

It must be noticed that use of young students with perfect hearing in this case study may limit generalizability of findings. More subjective evaluation experiments or epidemiological investigations covering different age and occupation groups may extend the generalizability of findings. In addition, subjects were given a video of the train passing during the noise exposure. It means that subjects could have identified which was high speed 
train and which was conventional train. This maybe introduced a bias into the subjective reporting of annoyance and activity disturbance.

\section{Conclusions}

Based on binaural recording of high-speed railway and conventional railway noises in a semi-free field, the noise annoyance and activity disturbance induced by maximal train pass-by events in China (six pass-by sounds with a constant interval over $15 \mathrm{~min}$ ) were investigated through laboratory subjective evaluation. With the same annoyance rating $(A)$ or activity disturbance rating $(D)$, the A-weighted equivalent sound pressure level $\left(L_{\text {Aeq }}\right)$ of $C R$ noise is approximately $7 \mathrm{~dB}$ higher than that of HR noise. Linear regression analysis between some acoustical parameters and $A$ (or $D$ ) suggests that the coefficient of determination $\left(\mathrm{R}^{2}\right)$ is higher with the instantaneous fast A-weighted sound pressure level $\left(L_{\text {AFmax }}\right)$ than that with $L_{\text {Aeq }}$. A combined acoustical parameter, $\quad L_{\mathrm{HC}}=1.74 L_{\mathrm{AFmax}}+0.008 L_{\mathrm{AFmax}}\left(L_{\mathrm{p}}-L_{\mathrm{Aeq}}\right)$, where $L_{\mathrm{p}}$ is the sound pressure level, was derived consequently, which could better evaluate the total railway noise, including HR and CR noise. More importantly, with a given $L_{\mathrm{HC}}$, the noise annoyance of $\mathrm{HR}$ and CR noise is the same. When there are combinations of various noise sources, there might be a scope of modifying $L_{\mathrm{HC}}$.

It should be pointed out that this study provides suggestive evidence, rather than a final proof. As a laboratory study involving students in their 20s (not a general population with naturally experienced levels of noise) with potential bias from being able to clearly identify which train was which, the results and conclusions above could have potential limitations. Further study is expected to elucidate conclusions above by additional measurements.

\section{Abbreviations}

CR: Conventional railway; HR: High-speed railway; MLR: Magnetic levitation railway; A: Annoyance rating; D: Activity disturbance rating; $L_{\mathrm{p}}$ : Sound pressure level; $L_{\mathrm{Aeq}}$ : A-weighted equivalent sound pressure level; $L_{\mathrm{A} 10}$ : A-weighted equivalent sound pressure level exceeded for $10 \%$ of the time of the measurement duration; LAFmax: Maximum level with a-weighted frequency response and fast time constant; $L_{\text {ASmax }}$ : Maximum level with a-weighted frequency response and slow time constant; $L_{\text {fpN }}$ : Effective perceived noise level; $L_{N}$ : Loudness level; $L_{H C}$ : Noise Level of high-speed railway and conventional railway; $L_{L}:$ Sound level in left ear of the binaural noise sample; $L_{R}$ : Sound level in right ear of the binaural noise sample; $L_{S}$ : Average value of $L_{L}$ and $L_{R}$ of the binaural noise sample; F: Fluctuation level; $R$ : Roughness level; $S$ : Sharpness level; SEL: Sound exposure level; $R^{2}$ : Coefficient of determination; $D$ : Distance between the noise sampling site and the outboard track.

\section{Competing interests}

The authors declare that they have no competing interests.

\section{Authors' contributions}

All authors have read the final version of the manuscript and have given final approval of this version of the manuscript to be published. GQD conducted the study design, data analysis and completed the final version of the manuscript. QLL planned the experiment, execution of data collection and prepared the first draft of the manuscript. ZGL assisted in the analysis of the study data, participated in the writing of the manuscript. JK participated in the study design, and critically reviewed the manuscript. All authors read and approved the final manuscript.

\section{Acknowledgements}

This research is supported by National Public Industry Research Fund in China (No. 200809142) and National Natural Science Foundation of China (No. 11174251).

\section{Author details}

${ }^{1}$ Institute of Environmental Pollution \& Control Technology, Zhejiang University, Hangzhou 310058, China. ${ }^{2}$ School of Architecture, University of Sheffield, Western Bank, Sheffield S10 2TN, UK.

Received: 29 July 2013 Accepted: 26 February 2014

Published: 7 March 2014

\section{References}

1. Mellet C, Létourneaux F, Poisson F, Talotte C: High speed train noise emission: Latest investigation of the aerodynamic/rolling noise contribution. J Sound Vib 2006, 293:535-546.

2. Nagakura K: Localization of aerodynamic noise sources of Shinkansen trains. J Sound Vib 2006, 293:547-556.

3. Kitagawa T, Nagakura K: Aerodynamic noise generated by Shinkansen cars. J Sound Vib 2000, 231:913-927.

4. U.S, U.S. Department of Transportation: Federal Railroad Administration Noise Characteristics of the Transrapid TR08 Maglev System 2002, Chapter 4:1-4.

5. De Coensel B, Botteldooren D, Berglund B, Nilsson ME, De Muer T, Lercher P. Experimental investigation of noise annoyance caused by high-speed trains. Acta Acustica United with Acustica 2007, 93:589-601.

6. Miedema HME, Vos H: Exposure-response relationships for transportation noise. J Acoust Soc Am 1998, 104:3432-3445.

7. Ono S: Measurement and analysis of railway noise in Japan. J Acoust Soc Jpn 2000, 21(E):345-348.

8. Lambert J, Champelovier P, Vernet I: Annoyance from high speed train noise: A social survey. J Sound Vib 1996, 193:21-28.

9. Chen X, Tang F, Huang Z, Wang G: High-speed maglev noise impacts on residents: A case study in Shanghai. Transp Res Part D: Transp Environ 2007, 12:437-448

10. Fastl H, Gottschling G: Subjective Evaluation of Noise Immissions from Transrapid. Liverpool, UK: Proceedings Internoise'96; 1996:2109-2114.

11. Gottschling $\mathrm{G}$, Fastl $\mathrm{H}$ : Acoustical simulation of 6-section-vehicles of the Transrapid. In the Progress of Acoustics, DAGA 1997, 97:254-255. In German.

12. Neugebauer D, Ortscheid J: Noise evaluation of the transrapid, in the progress of acoustics. DAGA 1997, 97:403-404. In German.

13. Vos J: Annoyance caused by the sounds of a magnetic levitation train. J Acoust Soc Am 2004, 115:1597-1608.

14. Di GQ, Wang QY, Li ZG, Jia L: Investigation into the subjective annoyance of intermittent noise. Acta Sci Circumst 2008, 28:1699-1703 (In Chinese).

15. Ministry of Environmental Protection of the People's Republic of China: Environmental Quality Standard for Noise, GB. Beijing: China Environmental Science Press; 2008:3096-2008.

16. Wang JF, Zhang ZP: The reflection of noise monitoring from Beijing to Tianjin high-speed railway. Noise and Vibration Control 2009, S2:211-213 (In Chinese).

17. Wang SM: Study on Evaluation Method of High-Speed Railway: A Case of Wuhang-Guangzhou High-Speed Railway, Dissertation for master's degree, Chapter 1, 2-10. Wuhan: Huazhong University of Science \& Technology; 2011. In Chinese.

18. Kurra S: Transportation noise annoyance - A simulated - environment study for road, railway and aircraft noises, part 1: overall annoyance. J Sound Vib 1999, 220:251-278

19. Nilsson ME, Andéhn M, Leśna P: Evaluating roadside noise barriers using an annoyance-reduction criterion. J Acoust Soc Am 2008, 124:3561-3567.

20. Vogt J, Vogt J: The relative impact of aircraft noise and number in a full-factorial laboratory design. J Sound Vib 2005, 282:1085-1100.

21. Sandrock S, Schütte M, Griefahn B: Mental strain and annoyance during cognitive performance in different traffic noise conditions. Ergonomics 2010, 53:962-971.

22. Clark JG: Uses and abuses of hearing loss classification. Am J Speech Lang Pathol 1981, 23:493-500. 
23. Michaud DS, Keith SE, Mc Murchy D: Annoyance and disturbance of daily activities from road traffic noise in Canada. J Acoust Soc 2008, 123:784-792.

24. International Organization for Standardization: Acoustics-Assessment of Noise Annoyance by Means of Socio-Acoustic Surveys, ISO/TS. Geneva: International Organization for Standardization; 2003. 15666:2003.

25. Pawlaczyk-Luszczynska M, Dudarewicz A, Szymczak W, Sliwinska-Kowalska M: Evaluation of annoyance from low frequency noise under laboratory conditions. Noise \& Health 2010, 12(48):166-181.

26. Kim J, Lim C, Hong J, Lee S: Noise-induced annoyance from transportation noise: short-term responses to a single noise source in a laboratory. J Acoust Soc Am 2010, 127:804-814.

27. Jeon JY, Lee PJ, You J, Kang J: Acoustical characteristics of water sounds for soundscape enhancement in urban open spaces. J Acoust Soc Am 2012, 131(3):2101-2109.

28. Zhang BJ, Di GQ: A study of the effect of visual sense on annoyance of noise. China Environ Sci 2000, 20(4):382-384.

29. Kryter KD: Acoustical, sensory, and psychological research data and procedures for their use in predicting effects of environmental noises. J Acoust Soc Am 2007, 122:2601-2614.

30. Fields JM, De Jong R, Brown AL, Flindell $I H$, Gjestland T, Job RFS, Kurra $S$, Lercher P, Schuemer-Kohrs A, Vallet M, Yano T: Guidelines for reporting core information from community noise reaction surveys. J Sound Vib 1997, 206:685-695.

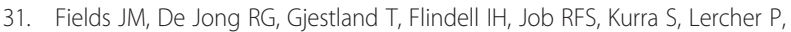
Vallet M, Yano T, Guski R, Felscher-suhr U, Schumer R: Standardized general-purpose noise reaction questions for community noise surveys: research and a recommendation. J Sound Vib 2001, 242:641-679.

32. Di GQ, Li ZG, Zhang BJ, Shi Y: Adjustment on subjective annoyance of low frequency noise by adding additional sound. J Sound Vib 2011, 330:5707-5715.

33. Di GQ, Liu XY, Lin QL, Zheng Y: The relationship between urban combined traffic noise and annoyance: an investigation in Dalian, north of China. Sci Total Environ 2012, 432:189-194.

34. State Bureau of Standardization of People's Republic of China: Electric, Sonic Properties and Measuring Methods for Sound Level Meters. Washington: U.S. Department of Transportation; 2007. GB 3785-83.

35. U.S. Department of Transportation: High-Speed Ground Transportation Noise and Vibration Impact Assessment. Appendix C, 1-2.

36. International Organization for Standardization: Acoustics-Procedure for Describing Air Noise Heard on the Ground. Geneva: ISO:3891-1978.

37. Zwicker E, Fastl H: Psycho-Acoustics, Facts and Models. Berlin: Springer-Verlag; 1990.

38. EU Commission: Directorate-General for Energy and Transport (EU CDGET). A study of European priorities and strategies for railway noise abatement 2002:8-17.

39. Ministry of the Environment Government of Japan: Environmental Quality Standards for Shinkansen Superexpress Railway Noise. Tokyo: Ministry of the Environment Government of Japan; 1993. Notification No. 91 of 1993.

40. Environmental Protection Administration of Taiwan: Emission Standards of Ground Transportation Noise. Taibei: Environmental Protection Administration of Taiwan; 2010. Decree No.0990003459D.

41. Kang J: Urban Sound Environment. London: Taylor \& Francis incorporating Spon; 2007.

doi:10.1186/1476-069X-13-12

Cite this article as: Di et al:: Annoyance and activity disturbance induced by high-speed railway and conventional railway noise: a contrastive case study. Environmental Health 2014 13:12

\section{Submit your next manuscript to BioMed Central and take full advantage of:}

- Convenient online submission

- Thorough peer review

- No space constraints or color figure charges

- Immediate publication on acceptance

- Inclusion in PubMed, CAS, Scopus and Google Scholar

- Research which is freely available for redistribution

Submit your manuscript at www.biomedcentral.com/submit
C Biomed Central 